\title{
Morte, linguagem e xamanismo em "Passagem das horas" de Álvaro de Campos
}

\author{
Death, language and shamanism in "Passage of the hours" \\ by Álvaro de Campos
}

\author{
AMANDA FIEVET MARQUES D \\ UNICAMP, Campinas, São Paulo, Brasil.
}

\begin{abstract}
Resumo: O presente trabalho tem como objetivo realizar uma análise da estrutura do poema "Passagem das horas" de Álvaro de Campos. Ao considerar o próprio desenvolvimento dos versos, a manifestação da morte na linguagem poética tal como aqui aparece, intenciona-se pensar de que forma a variação linguística no estilo de Álvaro de Campos é uma forma de morte e uma ruptura com relação à usual concepção de morte, a realização de um êxtase, que em termos semióticos, considera-se xamânico. A esse propósito, investigar-se-ão as particularidades de cada uma das três seções do poema. Primeiro, o eu lírico reconta as lembranças várias de sua própria vida, a partir da qual constitui-se um sensacionismo nostálgico. Segundo, o eu lírico angustia-se diante da morte, em termos de uma linguagem antitética e anafórica. Terceiro, o eu lírico realiza uma aclamação à morte ou um transe xamânico, pois ao personificar a morte em dama da noite, ama-a fervorosamente, demonstra o estatuto criativo e curativo da linguagem considerada delirante e, evidentemente, a indiscernibilidade entre criação, morte e delírio.
\end{abstract}

Palavras-chave: Morte; Linguagem; Xamanismo; Estilística; Álvaro de Campos.

\begin{abstract}
The present work aims to analyze the structure of the poem "Passage of the Hours" by Álvaro de Campos. In considering the development of the verses themselves, the manifestation of death in poetic language as it appears here, one intends to think of how linguistic variation in the style of Alvaro de Campos is a form of death and a rupture with respect to the usual concept of death, the constitution of an ecstasy, which in semiotic terms, is considered shamanic. In this regard, the particularities of each of the three sections of the poem will be investigated. First, the lyrical self retells the various memories of its own life, from which nostalgic sensation is created. Second, the lyrical self anguishes before death, in terms of an antithetic and anaphoric language. Third, the lyrical self performs an acclamation to death or a shamanic trance; by embodying death as a lady of the night, he loves her intensely, demonstrating the creative and curative status of language considered delirious, and evidently the indiscernibility between creation, death, and delirium.
\end{abstract}

Keywords: Death; Language; Shamanism; Stylistics; Álvaro de Campos. 


\section{Introdução}

O que se segue, assume-se de início como guia analítico, é a análise da estrutura do poema Passagem das horas de Álvaro de Campos. Há à composição do poema o estabelecimento de três unidades temáticas, que procuram construir a composição da existência da vida humana tal qual sentida pelo eu lírico: I) das lembranças constituídas ao longo do tempo (estrofes 1-3); II) da angústia pelo desaparecimento de tudo diante da morte no plano material e corpóreo (estrofes 4-10); III) da aclamação à morte, ou transe xamânico (estrofes 11-16). A distinção de tais seções realiza-se a partir das diferenças estilísticas entre elas. O desenvolvimento do trabalho intenciona delinear tais especificidades a fim de que o tema da morte tal qual expresso pelo poema de Álvaro de Campos, efetivado em sua linguagem, possa se expor.

\section{Das lembranças constituídas ao longo do tempo}

A primeira estrofe do poema reconstitui pelo esforço de memória do eu lírico, a qualidade singular de sua própria existência, oscilante a sua própria identidade, entre o composto de suas vivências e suas aspirações. Desse ponto de vista, o recurso estilístico das anáforas, pelas repetições do vernáculo "todos/todas" (versos 3, 4 e 5) efetuam, a nível linguístico, a qualidade básica da existência humana tal qual insinuada pelo título, Passagem das horas. O que as lembranças do eu lírico inicialmente demonstram, é que quem ele próprio é, os deleites e insatisfações que sorve, as imagens de lugares e portos, embora se repitam inesgotavelmente, provam, a cada novo repetir, um deslocamento de lugar e de sujeito. Tal movimento entre polos aparentemente opostos, mas que se unificam no decorrer das estrofes, reverbera também por efeito das antíteses, à medida que cada momento vivido é concomitantemente excesso e falta: "E tudo isso, que é tanto, é pouco para o que eu quero" (verso 7). O que se poderia denominar um aprendizado enunciado pela descrição das lembranças é vivido pelo eu lírico - pela pena de Álvaro de Campos que por diversas vezes goza da metafísica -, a partir da metafísica de uma vontade que é simultaneamente vontade de criar e destruir. $\mathrm{O}$ interesse em conduzir a análise do poema a cabo está em perceber que na seção três há propriamente a reunião entre as duas pulsões vitais, que são indiscerníveis quando da proposição de que mais viver, existir com intensidade no mundo tal como é consciência e dissipação súbita da consciência pelo fim da vida, é viver desejando a morte, inserindo-se como existente no repentino e inescapável de sua própria imprescindibilidade. Se não nos há escolha quanto à possibilidade da morte, a escolha mais alegre é amar e desejar a morte como à própria vida, de sorte que Passagem das horas tornase, ao longo das estrofes, uma ode à morte.

A segunda estrofe reconstitui a cada verso um elemento estrangeiro, nome de lugar ou sentença em língua estrangeira a que o eu lírico já haveria comparecido, que já teria escutado soar qual fosse proveniente "(...) do fundo de uma outra realidade" (verso 12). Além do recurso à enumeração por meio do qual aparecem "a entrada de Singapura", as Maldivas, Macau, Zanzibar, Madagascar, o Cabo da Boa Esperança, marcadamente utiliza-se 
a adjetivação por meio da visão, audição e tato. Assim, todos os lugares conciliam sua existência real, geográfica, à paisagem interior dos sentidos do sujeito, por meio da qual toda experiência estrangeira revela-se índice da multiplicidade ontológica que povoa o mundo. $\mathrm{O}$ eu sente-se muitos, a cada lugar em que esteve - o próprio lugar outra realidade um outro eu, já não mais existente, agora rememorado por esse que os têm como pálidas imagens do passado, recuperadas em vida no corpo do poema, "cor verde", "passagem cálida", "verduras", "tempestades". As realidades repetemse, ecoam no interior do sujeito, que as apreende como sensações infindáveis, marcadas no entanto, no tempo, pelo eu que as viveu, e agora existe apenas em imaginação. A morte torna-se assim, nas primeiras estrofes do poema, elemento necessário da passagem das horas, que não escoam sem a modificação inevitável do ser que nelas passa - as horas propriamente, $\mathrm{o}$ tempo, meio pelo qual o sujeito torna-se, nesse caso, o eu lírico reflexivo do poema, que se debruça sobre os imponderáveis da existência tal como sentida pelo ser humano.

Na terceira estrofe, anáforas e antítetes repetem-se à composição estilística, em que todos os lugares conhecidos e paisagens vividas não parecem esgotar as paisagens interiores ao próprio eu lírico: "Experimentei mais sensações do que todas as sensações que senti" (verso 21). O "sentir", nesse caso, aparece como relativo às ordens dos sentidos, a tudo o que o eu lírico conhece como elemento exterior, em contraposição à "experimentação" que the vem da infinita e variável realidade em si. A tópica do estrangeiro, no mundo e em si próprio, figura enfaticamente nesses versos, em que o eu lírico é mais despatriado nas fronteiras do seu próprio ser, mais herege nas margens de sua própria espiritualidade, mais excomungado nos limites de sua própria identidade, que nos possíveis fundamentos do mundo e seus confins. Além de encontrar em si a fonte inacabada de alteridade, o eu lírico assume sempre a passagem no tempo como fundamento variável à subjetividade. Quanto a esse aspecto, convém ressaltar o valor psicológico dos últimos versos dessa estrofe. O eu lírico está sempre cindido entre o excesso no modo como sorve as sensações e a falta oferecida pela vida, sentida na vivência tal qual conjugada ao elemento externo, ao acaso que reúne o eu lírico e o mundo: "Porque, por mais que sentisse, sempre me faltou que sentir / E a vida sempre me doeu, sempre foi pouco, e eu infeliz" (versos 22 e 23). Na formulação em elipse, em "sempre me faltou que sentir", revela-se na ocultação do pressuposto pelo leitor, do objeto direto "O", a explicitação da morte efetivada pelo estilo do poeta: sua dificuldade, ao experimentar-se como sujeito votado ao fado sensacionista, imerso em sensações, é a de unir todas as sensações, atá-las a um suposto sujeito unitário, afirmado pela identidade linguística do pronome pessoal e seus atributos. O que falta ao eu lírico é a certeza dessa atribuição, da identidade pressuposta, por isso não lhe falta " $\mathrm{O}$ " que sentir, justamente lhe falta "que sentir". Não há objeto votado a um sentido único. Falta-lhe que sentir, sentir como todo existente no mundo como se apresenta em calidez, verdura e tempestade, o que é sempre pouco e muito, exercício sensacionista e de linguagem, assunção da vida e morte da linguagem, do sujeito. 


\section{Da angústia diante da morte}

A quarta estrofe repete "desta/desta/ deste" três vezes, para em cada uma das vezes designar elementos distintos que reaparecem na existência do eu lírico, "estrada", "automóvel", "turbulência", "transfusão", que o perturbam quanto à qualidade fugaz com que passam por sua vida, pelo que ele se angustia e se indaga a respeito do que lhe restará disso tudo. Diferença e repetição constroem mais uma vez o valor de tais efeitos estilísticos, que realizam o próprio movimento da vida, da passagem das horas tal qual vivida pelo eu lírico, que agora se põe a rememorá-la, unificando-a na constituição do poema, discernindo-a pelo estilo. Assim se constitui entre as anáforas e os distintos elementos que as acompanham a angústia entre permanência de si como sujeito pensante, capaz de recordar, e a fugacidade da vida diante da morte inescapável: "Penso em que é que me ficará desta vida aos bocados, deste auge, / Desta estrada às curvas, deste automóvel à beira da estrada, deste aviso" (versos 25 e 26). A variação infinita ao que seguem os elementos anafóricos, sua qualidade fragmentária, indica a tentativa delineada entre a unidade que a vida oferece ao dotar todos os existentes de duração no tempo, concomitante à qualidade singular de todos os existentes, das pedras, às ararinhas, à borboleta, à consciência. A indiscernibilidade entre parte e todo marca a constituição do poema, e converte as estrofes em operador entre esses polos antitéticos, qual fossem tais versos os frágeis monumentos a tais dilemas e irresoluções de que se compõem as existências. Sendo afirmação de contradições torna-se sua proposta de ultrapassagem: é sempre a passagem das horas, parte e todo. A vida, desse ponto de vista, figura como “(...) turbulência tranquila de sensações desencontradas" (verso 27), "convergência iriada" (verso 28), "desassossego no fundo de todos os cálices" (verso 29), "angústia no fundo de todos os prazeres" (verso 30), "jogo de cartas fastiento entre o Cabo da Boa Esperança e as Canárias" (verso 32).

A quinta estrofe insere a oscilação de sentido sobre o significado estabelecido ao que seja a vida, pois jamais há certeza, para o eu lírico, de qual seja o seu destino na existência, qual seja o sentido que ele próprio deveria atribuir a ela, se é "pouco ou de mais" (verso 33), "de mais ou de menos" (verso 34). A tal falta de compromisso a um sentido suposto único, o eu lírico se indaga a respeito de sua própria conduta, se talvez o problema não seja da ordem da ausência de rigor consigo próprio, assunção de sentido, fosse religioso, fosse proveniente de filosofia racionalista, mística, fosse no decurso de vida desregrada, fosse na selvageria dos confrontos, fosse na pandegaria. No entanto, quanto ao eu lírico, ele próprio poetiza a condição múltipla dos sentidos potencialmente vivíveis, e assume a condição de indagador, a de quem se questiona "(...) se há outra significação para isto mais cómoda e feliz" (verso 38).

A sexta estrofe apresenta, por meio da sabedoria de Sileno, já uma aclamação à morte: "Seja o que for, era melhor não ter nascido" (verso 39). Tal como contada por Nietzsche em O Nascimento da Tragédia, Sileno seria o companheiro de Dionísio a quem o rei Midas perguntara "(...) qual dentre as coisas era a melhor e a mais preferível para o homem" (NIETZSCHE, 1992 , p.33). A criatura negava-se a responder ao permanecer em silêncio, mas 
sob insistência do rei tem de responder: "- Estirpe miserável e efêmera, filhos do acaso e do tormento! Por que me obrigas a dizer-te o que seria para ti mais salutar não ouvir? O melhor de tudo é para ti inteiramente inatingível: não ter nascido, não ser, nada ser. Depois disso, porém, o melhor para ti é logo morrer" (idem). Do ponto de vista de Nietzsche, tal sabedoria entre os gregos está a propósito aqui de pensar a arte trágica: apenas a cultura de um povo extremamente sensível à dor e tristeza imprescindíveis à existência poderia criar a tragédia, exaltação da vida em sua qualidade de mudança e dor.

Desse modo, a lenda do rei Midas e Sileno encarna sinteticamente, para Nietzsche, a produção grega da tragédia como elevação do horror da existência, a criação onírica dos deuses do Olimpo. É possível compreender, então, de que forma Sileno elogia a morte, e por extensão, a aclamação que nesse momento de Passagem das horas, o eu lírico faz à morte. Para Nietzsche, a arte trágica conjuga os elementos apolíneo e o dionisíaco, que depois será expulso pela dramaturgia racionalista de Eurípedes e a incorporação de elementos socráticos. Respectivamente, Apolo diz respeito ao “(...) mundo apolíneo da beleza (...). (...) Esse endeusamento da individuação, (...) a medida no sentido helênico" (ibid., p. 37); enquanto Dionísio encarna "(...) a dupla natureza de um cruel demônio embrutecido e de um brando e meigo soberano. (...) o fim da individuação (...)" (ibid., p. 67). Enfim, a tragédia tal como forjada por Ésquilo e Sófocles apresenta “(...) a consideração da individuação como causa primeira do mal, a arte como a esperança jubilosa de que possa ser rompido o feitiço da individuação, como pressentimento de uma unidade restabelecida" (idem).

Quanto à sexta estrofe, é em direção ao despedaçamento dionisíaco que ela parece desejar lançar-se, por meio da linguagem apolínea constituída pelo corpo poético. Fora do eu talhado por força e hábito de uma linguagem voltada a fins de representação e comunicação, a morte e a poesia que ela inspira permitem o eu lírico pender "para fora de todas as casas, de todas as lógicas e de todas as sacadas, / $E$ ir ser selvagem para a morte entre árvores e esquecimentos / Entre tombos, e perigos e ausência de amanhãs" (versos 43-5). A designação da morte e da poesia como dilaceração à individuação incitada por uma cultura decadente, do ponto de vista de Nietzsche, figura nos versos de Álvaro de Campos. A crítica implícita ao uso corriqueiro da linguagem faz-se nas repercussões de seu uso instrumentalizado a uma subjetividade niilista, votada ao nada querer. Aqui se pensar e sentir revelam-se em sua qualidade de interpenetração, tal reciprocidade condói o eu lírico desejoso da ruptura da linguagem a fins únicos de individuação, qual carpideira, dói-lhe a musa da vida.

Em honestidade metodológica é preciso ter à vista que as proposições aqui apresentadas a respeito dos versos dispostos em cada estrofe assumem apenas a tentativa de exposição de um ponto de vista, o que se delineia pela constituição de cada verso, e aqui, sua intrínseca relação com uma sabedoria sobre a morte, a implícita paráfrase de Sileno, tal qual supracitada. A dúvida que constantemente apavora o eu lírico a respeito de que destino assumir, ele próprio defronte essa tarefa impingida pela consciência no mundo, repete-se aqui na postura encenada aos 
dois primeiros versos da sétima estrofe. A fadiga, no entanto, que o acomete, a respeito da infinitude de versões que a sua vida poderia assumir, concomitante à própria impossibilidade de escolher vinculada à forte sensação de angústia -, resulta irônica; pois tanto quanto o excesso e a falta que sente em todos os afazeres, miudezas e detalhes quotidianos, tomaIhe de súbito no próprio gesto, também encenado, do cansaço. Paralisado pela abertura de escolha, ao limite, pergunta-se onde haveria liberdade absoluta, se até no sentido do fado, há o gesto impingido do rosto tombado aos braços, o corpo curvado em busca das lágrimas que não lhe vem: "Cruzo os braços sobre a mesa, ponho a cabeça sobre os braços, / E preciso querer chorar, mas não sei ir buscar as lágrimas..." (versos 48-9, grifos nossos). Assim, as rememorações relatadas até então pelo eu lírico, a favor de um eu cindido entre todos os lugares em que esteve, todas as sensações experimentadas, aparecem aqui à constituição da alma como fundamentalmente cindida pela infinita paralisação diante das escolhas potencialmente intermináveis: "Tenho a alma rachada sob o indicador curvo que Ihe toca... / Que há-de ser de mim? Que há-de ser de mim?" (versos 51-2).

Da perspectiva da oitava estrofe, o problema supracitado, da angústia diante da multiplicidade de escolhas possíveis a serem assumidas à constituição da própria existência, revela-se menos da ordem de uma perturbação inata ao eu lírico, e mais às atitudes e valores com que tem de se deparar ao viver na época em que vive, a de uma cultura "tão decadente, tão decadente, tão decadente..." (verso 57). O limite da agonia existencial mescla-se inevitavelmente à “(...) mágoa imensa do mundo (...)" (verso 56). Trata-se da tristeza também pelo fim de uma época, pela industrialização e advento da modernidade que mudam a face do mundo. $\mathrm{O}$ eu lírico pranteia a pobreza, a violência, a estupidez, em que a passagem das horas, se afeta os limites do indivíduo o faz também com a sociedade e sua história: "Jardins do século dezoito antes de 89, / onde estais vós, que eu quero chorar de qualquer maneira?" (versos 59 e 60).

A consideração do momento do lusco-fusco, o caminhar inevitável dos dias ao seu próprio fim, embala o eu lírico à assunção da verdade inescapável da morte, seja a da consciência, a dos ciclos que encerram e iniciam novas etapas, seja do decorrer dos fenômenos naturais ou da existência humana. Quanto às nona e décima estrofe, os versos criam uma paisagem de escurecimento que mescla a técnica e a natureza, posto que o cair da noite acompanha-se do acender das luzes, simultaneamente expondo o desprendimento da vida humana com relação à natureza. Há, de todo modo, como princípio componente em ambas, uma vitalidade incontornável que se renova duradouramente no decorrer da existência, tal como ela se configura comparativamente, em termos filosóficos, a título da leitura que Deleuze (1988) faz do conceito de eterno retorno em Nietzsche, como eterno retorno da diferença e não da identidade: "Acenderam as luzes, cai a noite, a vida substitui-se. / Seja de que maneira for, é preciso continuar a viver. Arde-me a alma como se fosse uma mão, fisicamente" (versos 63-5).

Ante todos os deslocamentos enunciados outrora pelo eu lírico, permanece explícito o dilema, a sensação antitética premente, entre seu próprio desejo 
simultâneo, feixe de continuidade e interrupção da existência. Excesso e falta, desejar partir e desejar seguir vivendo corroboram a sensação cíclica oferecida pela leitura do poema, pois apenas por essa insatisfação vital, de todo modo, segue-se vivendo como quem amasse inevitavelmente se insatisfazendo, contemplando a eterna ausência de resposta absoluta. Um ciclo aberto instaura a profusão de quem sempre parte, de sorte que o poema repete a oscilação entre partida e chegada, vida e morte, em sua instauração estilística, anáforas e antíteses: "Assim fico, fico... Eu sou o que sempre quer partir, / E fica sempre, fica sempre, fica sempre / Até à morte fica, mesmo que parta, fica, fica, fica..." (versos 69, 70-1). De fato, depreende-se inclusive uma concepção de tempo delineada pelas anáforas supracitadas. A vida, em um mundo pós morte de Deus, como eterna busca pelo sentido da existência, concebe-se apenas tal como sentida dessa forma na escrita poética. Desse ponto de vista, o procedimento capaz de revelar o problema da fugacidade da existência e a permanência da vida como princípio vital, é a criação poética. O que oferece a possibilidade de "ficar, ficar, ficar", ao menos enquanto durar a existência humana na história da Terra, é a arte. Assim, o poeta encontra no estilo o meio de expressar seu ponto de vista único, desejo de morrer pela incompreensão plena diante da inexistência de significado absoluto, e possibilidade de permanecer como poeta à ocasião de sua própria insuspeitada morte. O estilo só nasce com a morte da linguagem convencional. Assim, como a vida tal como sentida pelo eu lírico, só se expressa por meio desse ato simultâneo entre morte e criação na linguagem, a morte parece figurar apenas como positividade, como sustentável e suportável, se não compreensível e explicável, por meio do ato de linguagem. A criatura poeta sente-se liberta das amarras da fatalidade, pois criador na lavra constante de sua própria língua.

\section{Da aclamação à morte, ou transe xamânico}

Do encaminhamento delineado acima, é possível sugerir que há na estética forjada aqui pelo poeta uma percepção da morte como necessariamente amável, tendo em vista o alívio proporcionado às dores da vida. Assim, o único modo de escrever é, tanto pela fundação da poesia aqui de Álvaro de Campos, quanto pela possibilidade de lidar com o incompreensível e inefável na existência, por meio da incorporação da morte. Há, na lagoa plúmbea das reflexões do eu lírico, a visada sem temor à morte, que tangencia a edificação. No que designamos como a terceira seção de Passagem das horas, faz-se uma ode à morte, uma prece à eternidade dos mistérios que cercam a passagem irreversível entre consciência e inconsciência, vigília e sono perene. A atribuição de cura moral que tem o reconhecimento da beleza da morte aqui surge concomitantemente à proposição metafísica da arte - contrariamente a outros momentos da obra forjada por Fernando Pessoa sob a alcunha de Álvaro de Campos, em que a metafísica é satirizada -, a qual sugere que a poesia, em ato de morte à própria língua, caso houver, é o procedimento à própria superação da morte, em que a criação estilística aparece como realização fatal e transcendência à morte. 
Assim como outrora Apolo e Dionísio superavam a individuação e a identidade, pois em relação com o feixe de sensações vitais que ultrapassam os binarismos, o infinito das sensações da existência, que embora se intensifiquem ora em polo de dor e alegria, bem e mal, vida e morte, são absolutamente indizíveis sensações, e em seu estatuto de sensação, bela e terrível, revela-se apenas tal qual constitui-se na obra de arte, o eu lírico, em Passagem das horas, revela na aclamação à morte realizada à estrofe 11, amar na passagem, no devir, a própria certeza da eternidade da finitude, o que forja, no leitor, um intenso e complexo conjunto de sensações, que embora nasçam de polos bem definidos - vida e morte - perpassam elementos da natureza vários, paisagens, objetos, qualificações, isto é, pontos de vista nãohumanos e humanos.

Desse ponto de vista, como constituição semiótica, o poema habita uma zona criada, tencionar-se-ia bem sugerir, pelas práticas do xamanismo. De acordo com Mihály Hoppál, em "Xamãs e Símbolos", estudiosos da arte pré-histórica divergem quanto às teorias que especulam a respeito da origem do xamanismo: quais indícios das pinturas das cavernas comprovam o modo como apareceu a prática xamânica permanece como elemento hipotético. Um vetor de continuidade, no entanto, entre as teorias expostas por Hoppál é a transfiguração da imagem e sensações habituais do homem tal qual pensado pela convenção. É o uso de máscaras, visível nas pinturas pré-históricas, de trajes inusitados, metais variados, que constituem "provas tangíveis" da existência do xamanismo, explicitado pela arte (cf., HOPPÁL, 2013, p.41). Os trajes e acompanhamentos, balangandãs animalescos ou metálicos, máscaras, efetivam como significante, o significado mágico, que realiza o êxtase do homem na função de xamã ou feiticeiro: "The shaman performs a dance: he is in ecstasy. Having reached this state, his soul leaves his body. We hardly know anything about Upper Palaeolithic beliefs relating the soul"1 (MAKKAY, 1999, p. 71). $\mathrm{O}$ que se pretende propor aqui a partir dessas proposições é que a última seção de Passagem das horas realiza um êxtase, pois ao assumir fervoroso amor pela morte, qual confrade ideal, livra-se de toda a jeremiada anterior. $\mathrm{O}$ estilo aqui se torna imperativo, e a morte é qual a noite abençoada, aclamada em sua vinda libertadora de todos os desconfortos de uma existência não mais desemparada, à medida que acalentada pela certeza da morte. Em um mundo tornado científico e industrial, o eu lírico encontra na morte a fronteira do mistério, e qual feiticeiro, em seu culto à morte ("Torna-me humano, ó noite, torna-me fraterno e solícito. / (...) Vem, ó noite, e apaga-me, vem e afogame em ti" [versos 72 e 84]), restabelece a relação com o universo, recriando-o nos limites da linguagem poética.

De fato, a angústia experimentada na seção anterior dissolve-se aqui em prol de uma recepção plena à morte: "Vem para mim, ó noite, estende para mim as mãos, / E sê frescor e alívio, ó noite, sobre a minha fronte... / Tu, cuja vinda é tão suave que parece um afastamento" (versos 109, 110-1). Do ponto de vista semântico, tal como nos rituais xamânicos, os indonésios a título de exemplo, há aqui a capacidade de visão de um plano que transcende o material.

\footnotetext{
1 “O xamã faz uma dança: ele está em êxtase. Após alcançar esse estado, sua alma deixa seu corpo. Nós mal sabemos alguma coisa sobre as crenças do Paleolítico Superior relacionadas à alma" [tradução nossa].
} 
Vertentes do xamanismo indonésio designam como jalat (viagem), a atividade de transe realizada pelo xamã, capaz de fundir corpo e espírito em dança ritualística (cf., PORATH, 2013, p. 20). Convém notar fundamentalmente que as relações aqui propostas assumem a qualidade curativa das sessões xamânicas, e bem exatamente a reversão de determinada concepção de morte, como proposta na última seção de Passagem das horas. O eu lírico, distante está da possibilidade de assumir qualquer paixão triste em sua aclamação, mas unicamente intensidade na qualidade de sua existência ao considerar a finitude como imbuidora de beleza, permanente e irresoluto mistério: "Tu, palidamente, tu, flébil, tu, liquidamente, / Aroma de morte entre flores, hálito de febre sobre margens, / Tu, rainha, tu castelã, tu, dona pálida, vem..." (versos 115-7). Em extensão à relação proposta, de que há na poesia e no xamanismo a efetivação de alterações de estados de consciência e percepção, concebe-se em específico, a semelhança no que tange à concepção da morte como passagem, entrada reconhecida, proclamada, desejada em um reino espiritual. Em suma, contrariamente ao costume ocidental, de sustentar sobre o desatino a preponderância da consciência e racionalidade, tanto a poesia aqui estudada quanto a prática xamânica, viabilizam um estado de alteração da consciência e percpeção.

\section{Referências}

DELEUZE, Gilles. Diferença e repetição.

Tradução: Luiz Orlandi e Roberto Machado. Rio de Janeiro: Edições Graal, 1988.
International Society for Shamanistic Research, 2013.

MAKKAY, János. Two studies on early

Shamanism. Budapest: Mágankiad, 1999.

NIETZSCHE, Friedrich. O nascimento da tragédia: ou helenismo e pessimismo. Tradução, notas e posfácio: J. Guinsburg. São Paulo: Companhia das Letras, 2007.

PESSOA, Fernando. Álvaro de Campos: livro de versos. Lisboa: Estampa, 1993. Disponível em: http://arquivopessoa.net/textos/827. Acesso em: 25 dez. 2018.

PORATH, Nathan. "Not to be aware anymore": indigenous Sumatran ideas and Shamanic experiences of changed states of awareness/ consciousness. Anthropolofy of Consciousness, v. 24, n. 1, p. 7-31, May 2013. https://doi. org/10.1111/anoc.12001

Recebido em: 09/01/2019

Aceito em: 04/03/2019

Publicado em: 00/05/2019

\section{Autora:}

AMANDA FIEVET MARQUES

Possui graduação em Antropologia pelo Instituto de Ciências Humanas e Filosofia/UFF (2016), mestrado em Teoria e História Literária pelo Instituto de Estudos da Linguagem/UNICAMP (2018), onde atualmente é doutoranda em Teoria e História Literária. Tem experiência na área de Teoria Antropológica, Teoria Literária, Estética e Estilística, com ênfase nas obras de Marcel Proust e Louis-Ferdinand Céline no que tange à criação de uma teoria da arte imanente à obra, e do ponto de vista do estilo. Orcid: http://orcid.org/0000-0001-9863-5239

E-mail: amandafievet@gmail.com 